\title{
РОЛЬ РЫНКА ОБРАЗОВАТЕЛЬНЫХ УСЛУГ В СИСТЕМЕ НАЦИОНАЛЬНОЙ ЭКОНОМИКИ
}

\author{
(c) 2018 Рустамов Наваи Наваи оглы \\ Российский новый университет \\ 105005, г. Москва, ул. Радио, д. 22 \\ E-mail:navairu@yandex.ru
}

В статье рассмотрены теоретические подходы и представлена характеристика рынка образовательных услуг, как механизма экономических отношений между экономическими субъектами в отношении производства и потребления образовательных услуг. Автор отмечает, что продуктом функционирования рынка образовательных услуг является образовательная услуга, которая обладает рядом общих для услуги и специфических для сферы образования свойствами, а также такие компоненты, как покупатель, продуцент (продавец) и государственное регулирование.

Ключевые слова: рынок образовательных услуг, экономические отношения, воспитание и обучение лица, сфера услуг.

Введение. Сфера услуг, как ни одна из многих отраслей народного хозяйства, обусловлена влиянием социальных факторов, поскольку ориентирована на потребности населения [1]. В современных условиях одним из определяющих показателей конкурентоспособности национальной экономики является уровень развития рынка образовательных услуг. По мнению многих исследователей рациональная основа такой роли рынка образовательных услуг очевидна [2]. Экономическая наука в процессе своего развития рассматривала в качестве основы благосостояния наций различные категории: специализацию, инвестиции в производственные фонды и инфраструктуру, объемы производственных или природных ресурсов и пр [3]. Но неудачные попытки отдельных развивающихся государств обеспечить устойчивый экономический рост, несмотря на имеющиеся специализацию, ресурсы, большой объем инвестиций в развитие инфраструктурных объектов, продемонстрирова-

ли, что исключительно эти меры не позволяют достичь устойчивого развития в современных условиях мировой экономики. Все это привело к тому, что на первый план начали выступать иные механизмы, прежде всего, инновации, технологический прогресс и развитие человеческого капитала [4], которые как известно, основываются на образовании. То есть, без образования можно говорить об отсутствии квалифицированных рабочих кадров, науки, инноваций.

Основная часть. В данной связи важно рассмотреть сущность всех включенных в данный процесс экономических категорий. В отечественной и зарубежной экономической литературе существует много определений категории «рынок» (табл.1).

Как видно из таблицы 1, категория «рынок» рассматривается в области экономической науки, как «институт» или «механизм», который характеризуется «законам товарного производства и обращения». И поэтому важным для

Таблица 1. Подходы к определению категории «рынок»

\begin{tabular}{|c|c|}
\hline Автор подхода & Характеристика \\
\hline Маршалл, А. [5] & $\begin{array}{l}\text {... любая организация или механизм, обеспечивающий связь покупа- } \\
\text { телей и продавцов данного товара или услуги }\end{array}$ \\
\hline Милль, Дж. С. [6] & $\begin{array}{l}\text {... обмен, осуществляемый по законам товарного производства и } \\
\text { обращения }\end{array}$ \\
\hline Ф.Котлер [7] & ... совокупность существующих и потенциальных покупателей товара \\
\hline Кэмпбелл Р. Макконнелл, Брю С. Л. [8] & $\begin{array}{l}\text {... механизм / институт, который обеспечивает взаимодействие } \\
\text { продавцов (поставщиков) и покупателей (представителей спроса) } \\
\text { отдельных товаров и услуг }\end{array}$ \\
\hline Хейне П. [9] & ... набор взаимосвязей или процесс конкурентных торгов \\
\hline Самуэльсон П. А., Нордгауз В. & $\begin{array}{l}\text {... механизм, с помощью которого ... покупатели и продавцы взаимо- } \\
\text { действуют, чтобы определить цену и количество товара }\end{array}$ \\
\hline
\end{tabular}


эффективного развития системы образования является их правильное применение. Для понимания данного процесса целесообразно рассмотреть значение рынка образовательных услуг.

Традиционно, рынок образовательных услуг принято рассматривать как механизм экономических отношений между экономическими субъектами в отношении производства и потребления образовательных услуг [10]. Для рынка образовательных услуг обязательными являются такие компоненты, как покупатель, продуцент (продавец) и государственное регулирование. Мы систематизировали различные подходы к данной экономической категории, результаты которой представили в табл. 2.

Как показывают данные таблицы 2, в области экономики образования понятие «рынок образовательных услуг» рассматривается как система (совокупность) экономических взаимоотношений, которая, в свою очередь, также подчиняются законам товарного производства и обращения. То есть в условиях рынка «образовательная услуга» выступает объектом рыночной экономики, которая является неотъемлемой составляющей валового внутреннего продукта. При этом, можно отметить, что общим в определенные рынков является то, что это система экономических отношений в процессе купли-продажи того или иного товара (услуги) в области.

Рыночные отношения, которые складываются в сфере образования, формируют противоречия научных взглядов по определению терминологического аппарата функционирования данного рынка, состав его субъектов и объекта взаимоотношений. В современных исследованиях преобладает подход к определению понятия рынок образовательных услуг с позиции классической экономической теории, акцентируя на его качественных характеристиках, при- сущих категории «рынок» [15]. При этом рынок образовательных услуг рассматривается как система экономических отношений или непосредственно сама сфера, где происходят данные отношения по поводу производства и реализации образовательных услуг. Противоречия между мышлением и практической деятельностью, целью и результатом возникают постоянно и требуют разрешения. [16]

В начале XXI века в экономической науке сформированы новые подходы к определению рынка образовательных услуг, рассматривая его сквозь различные парадигмы, в соответствии с маркетинговым, институциональным и системным подходом:

1. Маркетинговый подход предусматривает формирование рынка образовательных услуг в соответствии с принципами и комплексом маркетинга.

2. В рамках институционального подхода исследуется поведение экономических субъектов рынка на основе таких факторов, как технологии, власть, частная собственность, корпорации, корпоративная система, правительство и т.д.

3. Системный подход предполагает исследование рынка образовательных услуг, как сложной социально-экономической системы, состоящей из определенных элементов.

Опираясь на исследования эволюции научных подходов, можно сделать вывод, что рынок образовательных услуг следует рассматривать как систему взаимодействующих элементов рынка, которые формируют систему финансового, кадрового, материально и инфраструктурного обеспечения процесса производства и реализации образовательных услуг на макро- и мезоуровне. Рынок образовательных услуг, как полифункциональный комплекс, выполняет

Таблица 2. Систематизация определения понятия «рынок образовательных услуг»

\begin{tabular}{|l|l|}
\hline \multicolumn{1}{|c|}{ Автор подхода } & \multicolumn{1}{|c|}{ Характеристика подхода } \\
\hline Терещенко Н.Н. [11] & $\begin{array}{l}\text {.. система взаимоотношений между учебными заведениями и другими } \\
\text { субектами рынка; во-вторых, это отношения по вопросам предоставле- } \\
\text { ния образовательных услуг, обмена, продажи и потребления образова- } \\
\text { тельных продуктов }\end{array}$ \\
\hline Арефьев, А.Л. [12] & $\begin{array}{l}\text {.. совокупность производственных отношений в отношении обмена } \\
\text { факторами производства или результатами труда }\end{array}$ \\
\hline Митрофанова, Т.Ю. [13] & $\begin{array}{l}\text {.. совокупность экономических взаимоотношений, складывающихся } \\
\text { между разноуровневыми субъектами по поводу купли-продажи образо- } \\
\text { вательных услуг }\end{array}$ \\
\hline Зверева А.И., Жданкина А.Ю. [14] & $\begin{array}{l}\text {.. принцип свободной купли-продажи результатов и условий хозяйство- } \\
\text { вания, принимаюих форму товара }\end{array}$ \\
\hline
\end{tabular}


ряд важных функций - регулирующую, информационную, социальную, экономическую, инновационную, интегративную, образовательно-научную, эффективное выполнение которых обеспечивает положительные экстерналии как для третьих лиц, так и для общества в целом.

Продуктом функционирования рынка образовательных услуг является образовательная услуга, которая обладает рядом общих для услуги и специфических для сферы образования свойствами. Одни исследователи рассматривают образовательную услугу как деятельность определенного лица или группы лиц [17]; другие - как набор определенных благ, которые получает потребитель услуги [18]; третьи - как комплекс определенных работ (операций), которые должны быть выполнены [19]; четвертые - как организован технологический процесс, в результате которого становится возможным наступления определенных положительных (хотя и нематериальных) результатов [20].

Образовательные услуги являются категорией не только экономической, но и социальной. Ведь в процессе потребления образовательной услуги происходит воспитание и обучение лица, способствует формированию у нее определенных духовных ценностей. Образование выступает как особый социокультурный институт, который позволяет молодым людям пройти процесс социализации (в том числе профессиональной), что является условием для дальнейшего полноценной жизни [21]. Потребление услуг, предоставляемых высшие учебные заведения, позволяет удовлетворить культурные потребности личности.

Проведенное исследование позволило нам провести систематизацию концептуальных подходов к определению понятия «образовательная услуга» (табл. 3).

Анализируя вышеизложенные определения, можно сказать, что целевая функция образования состоит в увеличении ценности человека как гражданина, личности, работника.

Специфические особенности образовательных услуг проявляется их классическими характеристиками (невозможность сохранения, непостоянство качества, неотделимость от источника, неосязаемость) и индивидуальными чертами (рисунок 1.).

Таким образом, образовательные услуги обладают особыми характеристиками, при этом, например, невозможность сохранения образовательных услуг может проявляться двояко. Прежде всего, невозможно оказать образовательные услуги заранее в полном объеме и аккумулировать их запас, как материальные товары, ожидая повышения спроса.

Кроме того, со временем человек забывает полученную информацию, знания. В связи с развитием научно-технического прогресса происходит также устаревание знаний.

Специфическими особенностями образовательных услуг являются [22]:

- высокая емкость интеллекта;

- отсрочка в определении результативности;

- зависимость результатов от жизни и условий будущей работы выпускников высших учебных заведений;

- относительная продолжительность оказания услуг;

- необходимость периодического и дальнейшего сопровождения услуг;

- зависимость услуг от места предоставления и места проживания потенциальных студентов;

- высокая стоимость;

- невозможность перепродажи

- необходимость взаимодействия учебных заведений всех уровней образования.

Таблица 3. Систематизация концептуальных подходов к определению понятия «образовательная услуга»

\begin{tabular}{|l|l|}
\hline \multicolumn{1}{|c|}{ Подход } & \multicolumn{1}{|c|}{ Характеристика } \\
\hline Классический рыночный & $\begin{array}{l}\text { определенный вид товара, особая потребительская стоимость процесса } \\
\text { труда преподавателя }\end{array}$ \\
\hline Маркетинговый & $\begin{array}{l}\text { объем учебной и научной информации, трансформируется в процессе } \\
\text { обучения в определенную сумму знаний }\end{array}$ \\
\hline Процессный & $\begin{array}{l}\text { процесс умственной деятельности преподавателя по обеспечению по- } \\
\text { требностей образовании }\end{array}$ \\
\hline Функциональный & $\begin{array}{l}\text { комплекс знаний, навыков, умений, которые накоплены и интерпрети- } \\
\text { рованы потребителями образовательных услуг согласно направлению } \\
\text { подготовки и уровню его развития }\end{array}$ \\
\hline
\end{tabular}




\section{Рынок образовательных услуг}

\section{Образовательные услуги}

\section{Совокупность умений, навыков, знаний и}

информации, которые используются для

удовлетворения многочисленных потребностей государства, общества, человека
Комплекс услуг, которые связаны с реализацией общественной миссии и главных целей образования

\section{Целевые функции образования - увеличение ценности человека как гражданина, работника, личности}

\section{Характеристики образовательных услуг}

\section{Неосязаемость

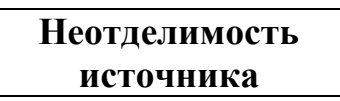

\section{Непостоянство качества}

\section{Невозможность сохранения}

Рис.1. Образовательные услуги на рынке образовательных услуг

При этом высокая интеллектуальная емкость может быть опосредована высоким уровнем товарности образовательной услуги как экономической формы хозяйствования [23].

Заметим, что определенные категории «рынок», «рынок образовательных услуг» и «рынок услуг» имеют общие характеристики для любой отрасли хозяйства, которые определяются взаимодействием между субъектами рынка [24].

Заключение. Таким образом, особенности сущности рынка образовательных услуг и его роли в развитии национальной экономики позволяет сделать вывод об изменении взглядов на данную проблему, о смене стратегических приоритетов ее развития в результате повышения значения взаимодействия участников системы школа-вуз.

Категории «рынок» и «рынок образовательных услуг» имеют общие черты для любой отрасли хозяйства и характеризуются взаимодействием между субъектами рынка с целью передачи прав собственности на товар или услугу на условиях применения законов товарного производства и обращения. Поэтому для системы образования мы уточняем это понятие так, что «рынок образовательных услуг» следует понимать как совокупность экономических отношений при потреблении образовательных услуг, возникающие между производителями образовательных услуг, школой, обеспечивающей наполнение высших учебных заведений, органы государственной власти, местного самоуправле- ния, корпорации, домохозяйства, некоммерческие организации и т.д., которые могут оплачивать предоставленные образовательные услуги полностью или частично.

Формирование и обеспечение нормального функционирования рынка образовательных услуг является обязательным условием развития национальной экономики любого государства, если ей необходимо продвигаться по пути технического и технологического развития. Особенно актуально данное утверждение в современных условиях глобализации мировых экономических отношений, при которых каждому государству важно занять достойное место в международном разделении труда, чтобы обеспечить конкурентоспособность своих компаний на мировых рынках, поэтому совершенно необходимо иметь для этого высококвалифицированных специалистов. Особенно, с учетом того, что на сегодняшний момент наблюдается стремительное развитие информационно-коммуникативных технологий. [25]

Сегодня страна, которая не может развивать знания и способности своих граждан, не только теряет конкурентные преимущества на различных рынках, но и вообще обречена на низкий уровень благосостояния. Поэтому важно понимать, что развитие рынка образовательных услуг является не только экономически целесообразным, а выступает важным и необходимым фактором повышения конкурентоспособности национальной экономики. 


\section{Библиографический список}

1. Рустамова И.Т. Управление устойчивостью функционирования предприятий сферы услуг на основании выбора стратегической зоны хозяйствования и прогноза потенциала деловой репутации // Экономика: вчера, сегодня, завтра. 2017. Т. 7. № 1А. С. 143-152.

2. Габышева, Л.К. Международные образовательные программы как фактор конкурентоспособности регионального университета // Общество: социология, психология, педагогика. 2017. № 6. С. 67-72.

3. История экономических учений /Под ред. В. Автономова, О. Ананьина, Н. Макашевой. Учеб. пособие. Москва. 2008.710 с.

4. Бажуткин Д.Г. Формирование и развитие рынка образовательных услуг высших учебных заведений: теория и методология: дис. д-ра экон. наук. Самара, 2010. 322 с.

5. Маршалл А. Основы экономической науки: монография. Москва. 2008. 832 с.

6. Милль Дж.С. Основы политической экономии: монография Москва. 1981.

7. Котлер Ф. Основы маркетинга. [Электронный ресурс]. Режим доступа: http://gtmarket.ru/laboratory/ basis $/ 5091$

8. Кэмпбелл Р. Макконнелл, Брю С.Л. Экономикс. Москва. 1992. Т.1. С. 61

9. Хейне П. Экономический образ мышления. Москва. 1991. С. 204

10. Бажуткин Д.Г. Формирование и развитие рынка образовательных услуг высших учебных заведений: теория и методология: дис. д-ра экон. наук. Самара, 2010. 322 с.

11. Терещенко Н.Н. Исследование рынка образовательных услуг учреждений высшей школы (на примере Красноярского и Алтайского краев): монография / Н.Н. Терещенко, Л.В. Бондаренко, Л.И. Подачина, Н.В. Фролова. Красноярск. 2005. 271с.

12. Арефьев А.Л. Российские вузы на международном рынке образовательных услуг. Москва. 2007. 355с.

13. Митрофанова Т.Ю. Разработка конкурентной стратегии вуза на рынке образовательных услуг: дис.... канд. экон. наук: 08.00.05 [Текст] / Т.Ю. Митрофанова. Санкт-Петербург. 2011.

14. Зверева А.И., Жданкина А.Ю. Состояние рынка образовательных услуг на региональном уровне: основные тенденции и показатели развития // Вестник НГИЭИ. 2016. № 1(56). С. 55-63.

15. Портер М. Конкуренция: пер. с англ. Москва. 2005. 608 с.; Рикардо Д. Начала политической экономии и налогового обложения. Москва. 2007. 960 с.

16. Кузнецов Ю.В., Капустина Н.В. Принципы исследования системы управления рисками // Вестник Мурманского государственного технического университета. 2010. Т. 13. № 1. С. 15-21.

17. Ананишнев В.М. Маркетинг образовательных услуг: монография. Москва. 2015. 348 с.

18. Резник С.Д. Система и механизмы управления конкурентоспособностью высшего учебного заведения: монография. Пенза. 2009. 147 с.

19. Березка Н.Н. Управление конкурентоспособностью вуза на основе модели маркетинга // Экономика и предпринимательство. 2017. № 3-1(80-1). С. 795-799.

20. Голикова Г.Л. Взаимосвязь системы высшего образования и потребностей рынка труда в условиях инновационной трансформации экономики России [Текст] / Г.Л. Голикова, И.А. Толстых // Регион: системы, экономика, управление. 2015. № 3(30). С.82-85.

21. Мозалевский А.Г. Управление сферой образовательных услуг региона в рамках интеграционного подхода: дис. канд. экон. наук. Тольятти, 2009. 188 с.

22. Беляков С.А. Организационно-экономический механизм устойчивого развития системы высшего профессионального образования в условиях формирования национальных университетов, системообразующих и инновационных вузов. Москва. 2007. 136 с.

23. Агранович М.Л. Проблемы и тенденции развития образования в Российской Федерации: Статистический информационно-аналитический сборник / М.Л. Агранович, О.Н. Кожевникова, О.В. Зайцева. Москва. 2014. $-474 \mathrm{c}$.

24. Assessing Quality in European Higher Education Institutions. / Ed. Chiara Orsingher. Heidelberg: Physica Verlag, 2006. $166 \mathrm{p}$

25. Фоменко Н.M., Капустина Н.В. Электронно-сетевые инструменты как инновационная составляющая коммуникационных связей публичного управления // Государственное и муниципальное управление. Ученые записки СКАГС. 2017. № 4. С. 68-72 